\title{
Cooking Practices
}

National Cancer Institute

\section{Source}

National Cancer Institute. Cooking Practices. NCI Thesaurus. Code C19733.

Methods of preparing foods and their role in health and disease. 